\title{
Effects of Agricultural Biomass Burning on Regional Haze in China: A Review
}

\author{
Hongmei Zhao ${ }^{1, *}$, Xuelei Zhang ${ }^{1}$, Shichun Zhang ${ }^{1}$, Weiwei Chen ${ }^{1}$, Daniel Q. Tong ${ }^{2,3}$ and \\ Aijun Xiu ${ }^{1,4}$ \\ 1 Key Laboratory of Wetland Ecology and Environment, Northeast Institute of Geography and Agroecology, \\ Chinese Academy of Sciences, Changchun 130102, China; zhangxuelei@neigae.ac.cn (X.Z.); \\ zhangshichun@iga.ac.cn (S.Z.); chenweiwei@iga.ac.cn (W.C.); xiuaijun@iga.ac.cn (A.X.) \\ 2 Center for Spatial Information Science and Systems, George Mason University, Fairfax, VA 22030, USA; \\ qtong@gmu.edu \\ 3 Cooperative Institute for Climate and Satellites, University of Maryland, College Park, MD 20740, USA \\ 4 Institute for the Environment, University of North Carolina at Chapel Hill, Chapel Hill, NC 27517, USA \\ * Correspondence: zhaohongmei@iga.ac.cn; Tel.: +86-431-8554-2314; Fax: +86-431-8554-2298 \\ Academic Editor: Xiaoyang Zhang \\ Received: 30 March 2017; Accepted: 16 May 2017; Published: 18 May 2017
}

\begin{abstract}
Burning agricultural straw before and/or after harvest is a common farming practice. Regional and extensive agricultural open field straw burning can cause serious air pollution events. This paper looks at the effects of biomass burning emission on regional haze that should be considered in the forecasting of regional haze. It describes the current state of crop residue burning in China, and analyzes the relationship between biomass burning and regional haze in terms of temporal/spatial patterns and chemical composition. Finally, some suggestions/recommendations are proposed for the recycling of agricultural straw to reduce the impact of biomass burning on regional haze and air quality. We suggest that prescribed open burning would be a more suitable solution in China. We hope that this report about biomass burning and regional haze will bring the issue to the attention of governments and other researchers.
\end{abstract}

Keywords: biomass burning; haze; agricultural straw; China

\section{Introduction}

Biomass burning is a long-standing agricultural practice, but increasing population and demand for agricultural land and food has had a profound effect on the extent of biomass burning. Globally, farmers use fire as a tool for the removal of agricultural waste and excess crop residue from fields [1]. In China, wood fuel and crop residue burning are the major sources of biomass burning, accounting for nearly $90 \%$ of the total biomass burning (based on dry weight), whereas grassland burning is only a minor source of biomass burning [2]. Approximately $140 \mathrm{Tg}$ of agricultural straw is burned in fields every year in China [3].

Biomass burning contributes large quantities of gases and particulate matter to the atmosphere. Emissions of gaseous pollutants and aerosol particles from biomass burning have a significant impact on air quality, human health, and climate $[4,5]$ and significantly contribute to the tropospheric radiation budgets on local, regional and even global scales [6-8]. Due to the substantial effect of biomass burning on air quality and climate, biomass burning emissions and their impact on air quality has been extensively studied in China through ground observation [4,9], satellite remote sensing [10,11], and model simulation $[12,13]$. There are three approaches to estimating biomass burning emissions: (1) combining statistical data (e.g., product of crop production, residue-to-production ratio, dry matter-to-crop residue ratio, the percentage of dry matter burned in fields, etc.) with the corresponding 
emission factors [14,15]; (2) based on the burned area detected by satellites [16,17]; and (3) based on fire radiative power (FRP) derived from satellite $[11,18]$. Generally, compared with statistical data, satellite data overestimate forest burning and underestimate crop residual biomass burning [2], because most biofuel is burned indoors and open field burning of small area is not detected by satellite [2]. In China, the average cultivated area of a farming household is only two acres $\left(0.001334 \mathrm{~km}^{2}\right)$ [19]. Open field burning occurs on a small scale and short duration, making it difficult to detect by satellite [14]. Liu et al. [11] estimated emissions from crop burning in fields across the North China Plain using the Moderate Resolution Imaging Spectroradiometer (MODIS) FRP. Their results were consistent with a previous study adopting an agricultural statistical approach [17], but significantly higher than emissions derived from the MODIS burned area product and Global Fire Emissions Database, Version 3.1 (GFEDv3.1, ORNL DAAC, Oak Ridge, TN, USA), respectively. In GFEDv3.1, emission estimation is based on MODIS burned area product. Van der Werf et al. [20] reported that emissions from agricultural fires were likely underestimated in GFEDv3 because some actual agricultural fire activity was not detected. Although study methodologies differ, the purpose of all the studies was to estimate biomass burning emission and analyze the effect of biomass burning on air quality.

In this paper, we review our present understanding about biomass burning and regional haze status in China in the past few years; discuss the relationship between biomass burning and regional haze in terms of spatio-temporal patterns and chemical composition; and finally provided some suggestions for reducing the effect of biomass burning on regional haze. We conclude that prescribed burning would be a more suitable solution for the disposal of large quantities of substantial agricultural straw in China.

\section{Biomass Burning and Regional Haze}

\subsection{Agricultural Open Field Biomass Burning in China}

Biomass burning is the burning of living and dead vegetation, including anthropogenic burning and natural fires [8]. Ninety percent of all biomass-burning is thought to be human initiated [8]. Anthropogenic burning is used in many applications, such as agricultural expansion, weed and residue burning, and harvesting practices. Natural fires include forest and grassland fires, caused by lighting [8]. Globally, it is estimated that $8700 \mathrm{Tg}$ of dry matter is burnt each year [7]. China is one of the greatest sources of biomass burning emissions [14], predominantly due to anthropogenic burning such as post-harvest agricultural open field biomass burning. A previous study has estimated that about $122 \mathrm{Tg}$ of crop residues are burned annually in China [14]. Since 1997, a series of regulations and laws to prohibit field burning were enacted by the Chinese government [2]. Farmers were encouraged to return crop residue to agricultural soils as fertilizer. However, despite these prohibitive laws, changes in practice were not widely adopted by farmers. For example, about $43 \%$ of crop residue was burned in the field in Suqian according to field investigations from 2001 to 2005 [21].

In China, crop residue burning accounts for a major part of total biomass burning [2]. There are several reasons for this. Firstly, China is an agricultural country, and produces large amounts of crop residue every year. Secondly, due to the high cost of straw collection, and limited room for straw storage, open field burning is the most effective option of all treatments. Finally, mechanized harvesting is another reason for crop residue burning in the field [21,22]. After mechanized harvesting, the height of the stubble left in the fields is about $30 \mathrm{~cm}$, making sowing difficult. Fragments are scattered throughout the field, making recovery difficult and reducing the potential for reuse as an industrial raw material.

Crop residue burning has an obvious spatial and temporal pattern in China. Based on the daily fire point derived from MODIS from 2002 to 2015, fire peak month and intensity were documented by Zhong et al. [23]. Most of the burning was observed in Eastern China. Previous studies also demonstrated that the North China Plain, Northeastern China and South China were the most important contributors to crop open burning in fields [17]. More than $80 \%$ of the agricultural 
burnings were in the agricultural regions, such as Anhui, Jiangsu, Shandong and Henan Provinces [10]. The temporal pattern of crop open burning is significantly associated with local sowing and harvest timing. In Mainland China, there were two distinct peaks corresponding to the summer and autumn harvest periods, especially in June and October [10]. The annual percentages of fires that occurred in June and October were $61-86 \%$ and $5-14 \%$, respectively, according to active fire products derived from MODIS from 2009 to 2010 [10]. In the Northern China Plain, over $75 \%$ of the annual fires occurred in June, with another smaller peak in early October [17].

Besides the obvious spatial and temporal patterns, emissions of gaseous pollutants and aerosol particles from biomass burning also have distinct aerosol characteristics. Emissions from biomass burning are known as a source of greenhouse gases such as carbon dioxide, methane, and nitrous oxide. Furthermore, aerosols emitted from biomass burning have high mass concentrations of $\mathrm{PM}_{2.5}$ (particles smaller than $2.5 \mu \mathrm{m}$ in diameters), OC (organic carbon), EC (elemental carbon) and $\mathrm{K}$ (potassium) [24]. Reports suggest that approximately $50-70 \%$ of the mass of all particle emissions from biomass burning is carbon, with OC and EC accounting for $55 \%$ and $8 \%$ of fine particle mass, respectively [25]. Trace inorganic species, mostly dominated by $\mathrm{K}, \mathrm{Cl}$ (chlorine) and $\mathrm{Ca}$ (calcium), account for approximately $10 \%$ of the mass of fresh smoke [25]. In China, the PM mass concentrations tend to be higher in winter, due to the high coal consumption [26]. The emissions of OC, EC and PM have two peaks, in May to June and October, after the harvesting of crops. Because the two periods are times of important agricultural activities, the increase of biomass burning, fertilizer and other agricultural activities during this time contributes a great amount of OC, EC and PM [26]. The sensitivity of gaseous pollutants and aerosol particle emissions from biomass burning to air quality was also simulated by Zhong et al. [27]. Their results suggest that the improvement of provincial-level emissions estimation of primary $\mathrm{PM}, \mathrm{SO}_{2}$ and $\mathrm{NO}_{X}$ should be considered in future studies.

Estimates of the effects of biomass burning on regional haze and air quality are based on emission inventories of agricultural straw burning. The emission inventory was calculated by multiplying the total amount of crop residue burnt by the corresponding emission factors. Methods for establishing an emission inventory include a bottom-up approach and a top-down approach [22]. The difference between the two approaches is the calculation of amount of crop residue burnt. In the bottom-up approach, the total amount of crop residue burnt was based on statistical data (e.g., product of crop production, residue-to-production ratio, dry matter-to-crop residue ratio, the percentage of dry matter burned in fields, etc.), whereas the top-down approach was based on satellite data. There are also two approaches about satellite data, one is based on the burned area, and the other is based on FRP. However, each of the methods has some limitations. Statistical data acquisition requires more time to analyze the collection of agricultural straw products, burnt fraction and burnt efficiency data, while satellite data perform poorly for small fires, especially for burned-area-based approach. Indoor biofuel burning and open field burning with a smaller area was not detected by satellite. FRP-based approach was developed in the past few years; it can calculate biomass burning emission inventory with higher temporal and spatial resolution, which is more suitable for model users. Nonetheless, the emission inventory is important for estimating the effect of agricultural residue burning on air quality and climate change [11].

\subsection{Relationship between Biomass Burning and Regional Haze}

Haze is defined as an air clarity phenomenon when visibility is less than $10 \mathrm{~km}$, caused by dry and invisible airborne fine particles according to the criteria prescribed by the China Meteorological Administration [28]. Biomass burning was the major contributor of local particulate matter, surface ozone, and regional haze [29]. Under economic development, fossil fuel consumption has also been increasing, and domestic biofuel has been decreasing in rural regions. As a result, the demand of fuel is lower, and more agricultural crop biomass is burned directly in the field [10]. Agricultural open field crop burning can result in intense local and regional haze and environmental pollution episodes, and can even affect climate change. A previous study documented that crop residue burning was 
responsible for intensive air pollution during harvest season [30]. The relationship between biomass burning and regional haze can be deduced from their temporal and spatial pattern and chemical composition over China.

Both biomass burning and regional haze show obvious temporal patterns. In general, aerosol concentrations tend to be higher in winter and lower in summer [31], with a secondary peak in spring [31]. Because of the increasing aerosol concentrations, the air quality has been deteriorating and hazy condition has been increasing in the past decades [26]. Regional haze is more frequent in winter and spring, and less frequent in summer [32], due to both increasing aerosol emissions from heating and stable atmospheric stratification in winter. However, previous studies indicated that crop burning emits large quantities of particulate matter and gaseous pollutants, and can seriously deteriorate air quality during the harvest season, especially in autumn [33]. Several active fires were detected in most parts of China during the harvest season [30], likely due to the common management practice of tilling directly after burning. Notably, in the past few years, October and June are the two months when both biomass burning and regional haze occurred in Northeastern China and Southeastern China, respectively [10]. In October, large quantities of gaseous pollutants and aerosol particles were emitted into the atmosphere during biomass burning episodes, and the stable atmospheric stratification prevented short term dispersion [10]; as a result, a regional haze event occurred after the biomass burning period.

Based on the surface visibility observations at meteorological stations in China, four major haze areas are identified: (1) Hua Bei Plain in Northern China, and the Guanzhong Plain; (2) Eastern China with the main body in the Yangtze River Delta area; (3) Southern China with most areas of Guangdong and the Pearl River Delta area; and (4) the Sichuan Basin in Southwestern China [26]. (Furthermore, Northeastern China has two sub-regions: the major grain producing area mainly in Heilongjiang Province and an old industrial region mainly in Liaoning Province; these could comprise a fifth regional haze area. Northeastern China and the North China Plain are often reported to suffer from heavy regional air pollution during harvest season. Increased crop residue burning is likely to be one of the reasons for an increase in regional haze in Northeastern China. A previous paper documented that Heilongjiang Province (in Northeastern China) was one of three high-density biomass burning regions [34,35]. Lower population and a large area of crop land in Heilongjiang Province caused most agricultural biomass to be disposed of by open burning in the field. In summary, the major regional haze distribution is focused in Eastern China, consistent with fire distribution in China.

While temporal and spatial patterns of agricultural burning and regional haze show the same trends, the chemical compositions of particles are another key parameter for estimating the effects of biomass burning on regional haze. Firstly, both biomass burning and regional haze are dominated by fine particles. Approximately $90 \%$ of particles emitted from biomass burning are $\mathrm{PM}_{2.5}$ [36]. A previous study revealed that atmospheric particles, especially fine particles from wheat straw burning in Northern China Plain, exert considerable influence on Beijing air quality [37]. Secondly, chemical compositions of particles emitted from agricultural straw burning contained notable amounts of some elements such as K and C. Previous studies have demonstrated that the combustion-derived particles emitted from wheat are enriched in $\mathrm{K}$ and $\mathrm{Cl}$, whereas the particles emitted from rice are largely carbonaceous [38]. Some fraction indicators were selected for assessing the relationship between biomass burning and regional haze. In general, high $\mathrm{PM}_{2.5} / \mathrm{PM}_{10}, \mathrm{OC} / \mathrm{EC}$, and $\mathrm{K} / \mathrm{EC}$ ratios were indices for biomass burning $[9,24]$. High ratios of $\mathrm{PM}_{10} / \mathrm{SO}_{2}$ and $\mathrm{CO} / \mathrm{SO}_{2}$ showed that air quality was heavily impacted by wheat straw burning, and these ratios can be employed as indicators of the contribution of wheat straw burning to the degradation of Beijing air quality [37].

Here, we focus on Changchun City as a case study. There are two reasons for choosing Changchun City: (1) it lies in a high-frequency fire region, and suffers from regional haze; and (2) fire locations and $\mathrm{PM}_{2.5}$ concentrations can be monitored simultaneously. $\mathrm{PM}_{2.5}$ concentrations, fire points, temperature and precipitation during harvesting season and the regional haze period in Changchun City in 2014 and 2015 are shown in Figure 1. The $\mathrm{PM}_{2.5}$ concentrations were downloaded from Air Quality Online 
Monitoring of China [39]. There are 10 measurement stations in Changchun for long time online monitoring. The fire points were derived from the NASA Earth Observatory's Active Fire Data [40]. In general, harvesting season was from 1 October to 10 November, with biomass burning occurring one week later than harvesting. The $\mathrm{PM}_{2.5}$ concentrations and fire points presented same temporal pattern both in 2014 and 2015 (Figure 1). Figure 1 shows a high $\mathrm{PM}_{2.5}$ concentration during biomass burning. The $\mathrm{PM}_{2.5}$ concentration peak in 2015 was later than that in 2014, due to the later harvesting and biomass burning in 2015. $\mathrm{PM}_{2.5}$ concentrations and fire points were lower in 2015 compared with 2014, because of serious prohibition of biomass burning and collection of agricultural residue by the local government in 2015. Nevertheless, a strong peak occurred on 9 November, because most agricultural residue was abandoned in the fields waiting for collection, while weather reports predicted heavy snow on the night of 9 November. If the agricultural residues were not burned before the heavy snow, they would have remained in the field until next spring, thereby delay sowing. Consequently, most farmers burned the residue before 9 November in order to dispose of the residue in time, resulting the emission of large quantities of particulate matter and pollutant gases into the atmosphere in one day. This triggered a regional haze event. Besides biomass burning emission, the weather conditions (temperature and precipitation) between 2014 and 2015 were the same. It suggested that dramatically biomass burning contributed the regional haze in Changchun city. If a prescribed burning had been conducted, and the crop residue was burned over a longer time period instead of on one or two days, there would have been no $\mathrm{PM}_{2.5}$ concentration peak.

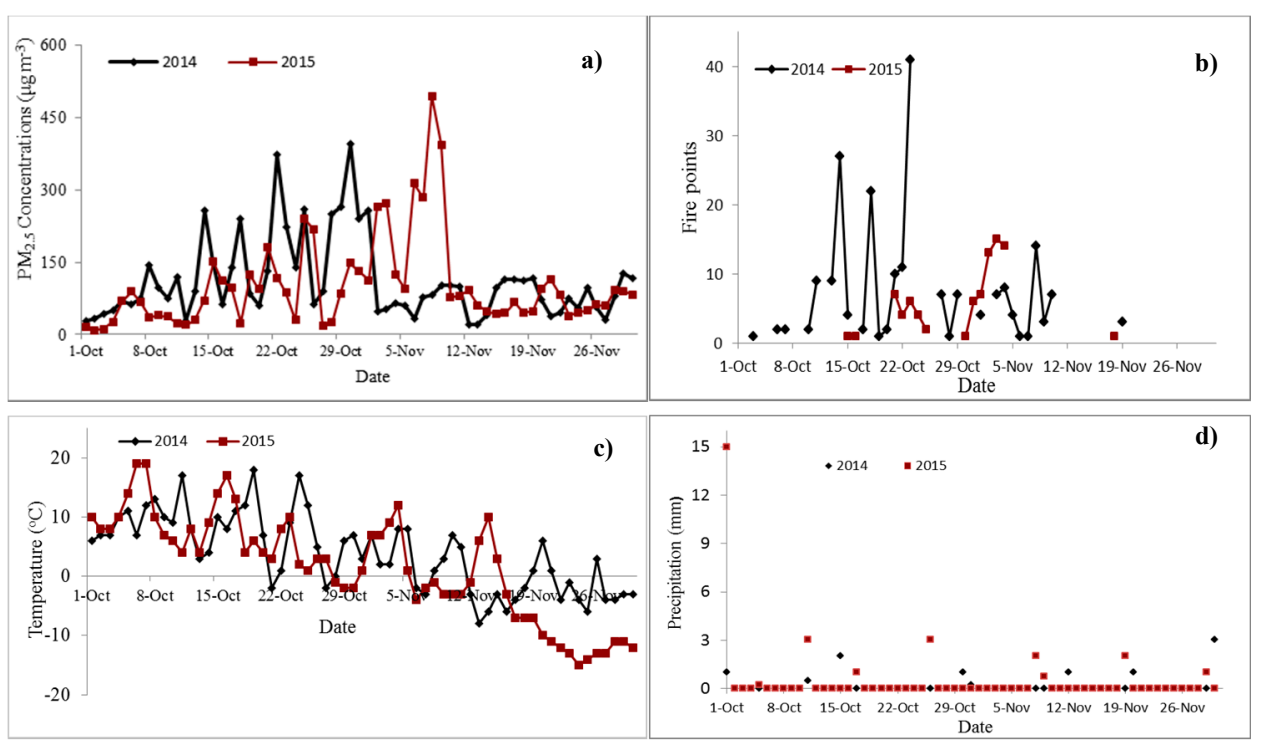

Figure 1. $\mathrm{PM}_{2.5}$ concentrations (a), fire points (b), temperature (c) and precipitation (d) in Changchun city during harvesting season and the regional haze period in 2014 and 2015.

Despite the qualitative understanding of biomass burning and regional haze, the determination of key parameters needed for estimating the effects of biomass burning on regional haze is not straightforward. Generally, methods to determine the impact of biomass burning on air quality and visibility include [41]: (1) emission inventories; (2) air quality monitoring instruments to measure smoke concentrations in near-real-time; and (3) filter-based monitoring techniques and receptor-oriented methods that quantify burning smoke contribution to air pollution based on the chemical characteristics of smoke particles or their spatial/temporal variability [41]. Emissions from biomass burning vary depending on fuel type and moisture content, combustion phase, wind conditions, and other meteorological conditions. In addition, biomass-burning aerosols can evolve rapidly as they disperse, so it is difficult to relate agricultural straw burning to the regional haze. A key 
issue is finding solutions to deal with large quantities of agricultural straw, in order to reduce the effect of agricultural burning on regional haze.

\subsection{Solutions for Agricultural Straw}

Although agricultural open field burning was prohibited by the government, the effectiveness of this ban is limited and new solutions should be implemented. Since agricultural straw is very useful, there are some suitable solutions, as follows:

(1) Electricity generation: Electricity generated by biomass generally offers a favorable price, high efficiency and low emissions, but often has unfavorably high land and water usage. Sixty-two countries produce electricity from biomass [42]. In China, the maximum power generation potential of agricultural biomass resources is $70,465.35 \mathrm{MW}$, and the preferred development areas include Heilongjiang, Henan, Shandong and Jilin provinces [43]. In fact, electricity has been generated in Jilin Provence using this method since 2015.

(2) Animal feed supply [44]: Besides cellulose, straw contains hemicellulose and lignin which are palatable to ruminants such as cows.

(3) Bio-ethanol production: Rice straw can be used in bio-ethanol production, bringing additional income and allowing sustainable utilization [45].

(4) Returning straw to the field: This solution is an important soil management practice to improve soil fertility. For example higher soil organic carbon, nitrogen, and phosphorus contents were observed following straw-returning than under normal tillage.

These solutions are rarely adopted in China because large volumes of agricultural straw are hard to collect in a short term after harvest, yet timely removal after the harvest is critical to avoiding missing the sowing season. Furthermore, much room is needed for agricultural straw storage before further processing. Therefore, open field burning is widely used as an inexpensive means of disposal in most parts of China.

Here we propose that prescribed open burning would be a more suitable solution in China. Prescribed burning is the process of planning and applying fire to a predetermined area, under specific environmental conditions, to achieve a desired outcome [46]. It has been used widely in grassland and forest ecosystem as fuel management tool by reducing the intensity, size and damage of wildfire [46]. There are several reasons for this: (1) prescribed burning has been used widely in grassland and forest ecosystem as a fuel management tool by reducing the intensity, size and damage of wildfire [47,48]; and (2) prescribed burning is an inexpensive and efficient means to clean agricultural straw. However, compared with common open field burning, execution of prescribed burning should consider conditions including wind speed, diffusion of gaseous pollutants and particle matter, air quality, and rainfall forecasts. A lower wind speed would be better than a higher wind speed, to allow control of the area being burned. Atmospheric conditions should be favorable for diffusion, for example before periods of cold air. Prescribed burning should be prohibited during fog or temperature inversion conditions. Background air quality should also be considered. Prescribed burning should be conducted during good or moderate air quality and prohibited during poor or hazardous air quality. Rainfall after the prescribed burning would help reduce particle emissions. Clearly, prescribed burning should be carried out far away from residential areas, shrub land and highways. Heavy smoke from agricultural straw burning should have no effect on highway or airline visibility. Finally, prescribed burning of agricultural straw should be managed by both farmers and governments: farmers carry out the prescribed burning, and the government provides information about when and where agricultural straw should be burned.

\section{Conclusions}

China is a large agricultural country and agricultural burning is a common practice. Biomass burning, especially agricultural burning has an important impact on regional air quality. This paper 
looked at the effects of biomass burning emissions on regional haze. In China, large quantities of agricultural straw are open burned after harvest, causing serious air pollution, especially in the past few years. Furthermore, the air quality has been deteriorating and hazy conditions have been increasing in the past decades. Agricultural burning and regional haze have followed the same temporal and spatial patterns over China. To reduce the effect of agricultural burning on air quality and regional haze, some solutions are proposed for agricultural straw reuse. We suggest that prescribed open burning would be a more suitable solution in China. This review of biomass burning and regional haze is needed to bring the issue to the attention of governments and other researchers.

Acknowledgments: This work is financially supported by the Natural Science Foundation of Jilin Province (No. 20150101010JC), the "Strategic Priority Research Program" of the Chinese Academy of Sciences (No. XDB05020304), and the National Natural Science Foundation of China (No. 41575129).

Author Contributions: The study was completed with cooperation among all authors: Hongmei Zhao conceived and designed the research topic and wrote the manuscript. Xuelei Zhang, Shichun Zhang, Weiwei Chen, Daniel Q. Tong, and Aijun Xiu collaborated in discussing the manuscript and providing editorial advice.

Conflicts of Interest: The authors declare no conflict of interest.

\section{References}

1. McCarty, J.; Korontzi, S.; Justice, C.O.; Loboda, T. The spatical and temporal distribution of crop residue burning in the contiguous United States. Sci. Total Environ. 2009, 407, 5701-5712. [CrossRef] [PubMed]

2. Yan, X.Y.; Ohara, T.; Akimoto, H. Bottom-up estimate of biomass burning in mainland China. Atmos. Environ. 2006, 40, 5262-5273. [CrossRef]

3. Cao, G.L.; Zhang, X.Y.; Wang, Y.Q.; Zheng, F.C. Estimation of emissions from field burning of crop straw in China. Chin. Sci. Bull. 2008, 53, 784-790. [CrossRef]

4. Li, W.J.; Shao, L.Y.; Buseck, P.R. Haze types in Beijing and the influence of agricultural biomass burning. Atmos. Chem. Phys. 2010, 10, 8119-8130. [CrossRef]

5. Keywood, M.; Kanakidou, M.; Stohl, A.; Dentener, F.; Grassi, G.; Meyer, C.P.; Torseth, K.; Edwards, D.; Thompson, A.M.; Lohmann, U.; et al. Fire in the Air: Biomass Burning Impacts in a Changing Climate. Crit. Rev. Environ. Sci. Technol. 2013, 43, 40-83. [CrossRef]

6. Li, X.; Wang, S.; Duan, L.; Hao, J.; Li, C.; Chen, Y.; Yang, L. Particulate and trace gas emissions from open burning of wheat straw and corn stover in China. Environ. Sci. Technol. 2007, 41, 6052-6058. [CrossRef] [PubMed]

7. Andreae, M.O. Biomass burning: Its history, use, and distribution and its impact on environmental quality and global climate. In Global Biomass Burning: Atmospheric, Climatic, and Biospheric Implications; Levine, J.S., Ed.; MIT Press: London, UK, 1991; pp. 3-21.

8. Biomass Burning Feature. Available online: https://earthobservatory.nasa.gov/Features/BiomassBurning/ (accessed on 20 April 2017).

9. Chen, Y.; Xie, S. Characteristics and formation mechanism of a heavy air pollution episode caused by biomass burning in Chengdu, Southwest China. Sci. Total. Environ. 2014, 473, 507-517. [CrossRef] [PubMed]

10. Zha, S.P.; Zhang, S.Q.; Cheng, T.T.; Chen, J.M.; Huang, G.H.; Li, X.; Wang, Q.F. Agricultural Fires and their potential impacts on regional air quality over China. Aerosol Air Qual. Res. 2013, 13, 992-1001.

11. Liu, M.; Song, Y.; Yao, H.; Kang, Y.; Li, M.; Huang, X. Estimating emissions from agricultural fires in the North China Plain based on MODIS fire radiative power. Atmos. Environ. 2015, 112, 326-334. [CrossRef]

12. Yamaji, K.; Li, J.; Uno, I.; Kanaya, Y.; Irie, H.; Takigawa, M.; Komazaki, Y.; Pochanart, P.; Liu, Y.; Tanimoto, H.; et al. Impact of open crop residual burning on air quality over Central Eastern China during the Mount Tai Experiment 2006 (MTX2006). Atmos. Chem. Phys. 2010, 10, 7353-7368. [CrossRef]

13. Cheng, Z.; Wang, S.; Fu, X.; Watson, J.G.; Jiang, J.; Fu, Q.; Chen, C.; Xu, B.; Yu, J.; Chow, J.C.; et al. Impact of biomass burning on haze pollution in the Yangtze River delta, China: A case study in summer 2011. Atmos. Chem. Phys. 2014, 14, 4573-4585. [CrossRef]

14. Streets, D.G.; Yarber, K.F.; Woo, J.H.; Carmichael, G.R. Biomass burning in Asia: Annual and seasonal estimates and atmospheric emissions. Glob. Biogeochem. Cycle 2003, 17, 1099. [CrossRef] 
15. Li, J.; Li, Y.; Bo, Y.; Xie, S. High-resolution historical emission inventories of crop residue burning in fields in China for the period 1990-2013. Atmos. Environ. 2016, 138, 152-161. [CrossRef]

16. Zhang, X.; Kondragunta, S.; Schmidt, C.; Kogan, F. Near real time monitoring of biomass burning particulate emissions (PM2.5) across contiguous United States using multiple satellite instruments. Atmos. Environ. 2008, 42, 6959-6972.

17. Huang, X.; Li, M.; Li, J.; Song, Y. A high-resolution emission inventory of crop burning in fields in China based on MODIS Thermal Anomalies/Fire products. Atmos. Environ. 2012, 50, 9-15.

18. Zhang, X.; Kondragunta, S.; Ram, J.; Schmidt, C.; Huang, H. Near-real-time global biomass burning emissions product from geostationary satellite constellation. J. Geophys. Res. 2012, 117, D14201.

19. National Bureau of Statistics of China. China Statistic Yearbook; China Statistics Press: Beijing, China, 2013.

20. Van der Werf, G.R.; Randerson, J.T.; Giglio, L.; Collatz, G.J.; Mu, M.; Kasibhatla, P.S.; Morton, D.C.; DeFries, R.S.; Jin, Y.; Van Leeuwen, T.T. Global fire emissions and the contribution of deforestation, savanna, forest, agricultural, and peat fires (1997-2009). Atmos. Chem. Phys. 2010, 10, 11707-11735. [CrossRef]

21. Yang, S.; He, H.; Lu, S.; Chen, D.; Zhu, J. Quantification of crop residue burning in the field and its influence on ambient air quality in Suqian, China. Atmos. Environ. 2008, 42, 1961-1969. [CrossRef]

22. Li, J.; Bo, Y.; Xie, S. Estimating emissions from crop residue open burning in China based on statistics and MODIS fire products. J. Environ. Sci. 2016, 44, 158-170. [CrossRef] [PubMed]

23. Zhong, F.; Su, Q.; Zhou, R.; Yi, M.; Wu, Q.; Yan, Y. Impact of crop straw burning on urban air quality based on WRF-Chem simulations. Clim. Environ. Res. 2017, 22, 149-161. (In Chinese)

24. Zhao, H.M.; Tong, D.Q.; Lee, P.; Kim, H.; Lei, H. Reconstructing Fire Records from Ground-Based Routine Aerosol Monitoring. Atmosphere 2016, 7, 43. [CrossRef]

25. Reid, J.S.; Koppmann, R.; Eck, T.F.; Eleuterio, D.P. A review of biomass burning emissions part II: Intensive physical properties of biomass burning particles. Atmos. Chem. Phys. 2005, 5, 199-825. [CrossRef]

26. Zhang, X.Y.; Wang, Y.Q.; Niu, T.; Zhang, X.C.; Gong, S.L.; Zhang, Y.M.; Sun, J.Y. Atmospheric aerosol compositions in China: Spatial/temporal variability, chemical signature, regional haze distribution and comparisons with global aerosols. Atmos. Chem. Phys. 2012, 12, 779-799. [CrossRef]

27. Zhong, M.; Saikawa, E.; Liu, Y.; Naik, V.; Horowitz, L.W.; Takigawa, M.; Zhao, Y.; Lin, N.; Stone, E.A. Air quality modeling with WRF-Chem v3.5 in East Asia: Sensitivity to emissions and evaluation of simulated air quality. Geosci. Model Dev. 2016, 9, 1201-1218.

28. China Meteorological Administration. Ground Meteorological Observations; Meteorological Press: Beijing, China, 1979.

29. Tang, H.Y.; Liu, G.; Zhu, J.G.; Han, Y.; Kobayashi, K. Seasonal variations in surface ozone as influenced by Asian summer monsoon and biomass burning in agricultural fields of the northern Yangtze River Delta. Atmos. Res. 2013, 122, 67-76. [CrossRef]

30. Huang, X.; Song, Y.; Li, M.; Li, J.; Zhu, T. Harvest season, high polluted season in East China. Environ. Res. Lett. 2012, 7, 044033. [CrossRef]

31. Wang, Y.Q.; Zhang, X.Y.; Sun, J.Y.; Zhang, X.C.; Che, H.Z.; Li, Y. Spatial and temporal variations of the concentrations of $\mathrm{PM}_{10}, \mathrm{PM}_{2.5}$ and $\mathrm{PM}_{1}$ in China. Atmos. Chem. Phys. 2015, 15, 13585-13598. [CrossRef]

32. $\mathrm{Fu}, \mathrm{H}$; Chen, J. Formation, features and controlling strategies of severe haze-fog pollutions in China. Sci. Total Environ. 2017, 578, 121-138. [CrossRef] [PubMed]

33. Li, J.; Song, Y.; Mao, Y.; Mao, Z.; Wu, Y.; Li, M.; Huang, X.; He, Q.; Hu, M. Chemical characteristics and source apportionment of $\mathrm{PM}_{2.5}$ during the harvest season in eastern China's agricultural regions. Atmos. Environ. 2014, 92, 442-448.

34. Qin, X.; Yan, H.; Zhan, Z.; Li, Z. Charactering vegetative biomass burning in China using MODIS data. Int. J. Wildl. Fire 2014, 23, 69-77. [CrossRef]

35. Zhao, H.M.; Tong, D.Q.; Gao, C.Y.; Wang, G.P. Effects of dramatic land use change on gaseous pollutants emissions from biomass burning in Northeastern China. Atmos. Res. 2015, 153, 429-436. [CrossRef]

36. Deng, C.R. Identification of Biomass Burning Source in Aerosols and the Formation Mechanism of Haze. Ph.D. Thesis, University of Fudan, Shanghai, China, 15 April 2011.

37. Li, L.J.; Wang, Y.; Zhang, Q.; Li, J.X.; Yang, X.G.; Jin, J. Wheat straw burning and its associated impacts on Beijing air quality. Sci. China Earth Sci. 2008, 51, 403-414. [CrossRef]

38. Hays, M.D.; Fine, P.M.; Geron, C.D.; Kleeman, M.J.; Gullett, B.K. Open burning of agricultural biomass: Physical and chemical properties of particle-phase emissions. Atmos. Environ. 2005, 39, 6747-6764. [CrossRef] 
39. Air Quality Online Monitoring of China. Available online: https://www.aqistudy.cn/ (accessed on 15 December 2015).

40. The NASA Earth Observatory's Active Fire Data. Available online: https://earthdata.nasa.gov/earthobservation-data/near-real-time/firms/active-fire-data (accessed on 30 December 2016).

41. Sandberg, D.V.; Ottmar, R.D.; Peterson, J.L.; Core, J. Wildland Fire on Ecosystems: Effects of Fire on Air; U.S. Department of Agriculture, Forest Service, Rocky Mountain Research Station: Ogden, UT, USA, 2002; Volume 5, p. 79.

42. Evans, A.; Strezov, V.; Evans, T.J. Sustainability considerations for electricity generation from biomass. Renew. Sustain. Energy Rev. 2010, 14, 1419-1427. [CrossRef]

43. Liu, Z.B. Research on Potential Assessment and Industry Development of Biomass Power Generation in China. Ph.D. Thesis, Chinese Academy of Agricultural Sciences, Beijing, China, 29 November 2015.

44. Abdel-Aziz, A.N.; Salem, A.Z.M.; EI-Adawy, M.M.; Camacho, L.M.; Kholif, A.E.; Elghandour, M.M.Y.; Borhami, B.E. Biological treatments as a mean to improve feed utilization in agriculture animals-An overview. J. Integr. Agric. 2015, 14, 534-543. [CrossRef]

45. Singh, R.; Srivastava, M.; Shukla, A. Environmental sustainability of bioethanol production from rice straw in India: A review. Renew. Sustain. Energy Rev. 2016, 54, 202-216. [CrossRef]

46. Prescribed Burning-Department of Parks and Wildlife. Available online: https://www.dpaw.wa.gov.au/ management/fire/prescribed-burning (accessed on 25 April 2017).

47. Valko, O.; Deak, B.; Magura, T.; Torok, P.; Kelemen, A.; Toth, K.; Horvath, R.; Nagy, D.D.; Debnar, Z.; Zsigrai, G. Supporting biodiversity by prescribed burning in grasslands-A multi-taxa approach. Sci. Total Environ. 2016, 572, 1377-1384. [CrossRef] [PubMed]

48. Zhuo, N.; Sun, C. Forest management with wildfire risk, prescribed burning and diverse carbon polices. For. Policy Econ. 2017, 75, 95-102.

(C) 2017 by the authors. Licensee MDPI, Basel, Switzerland. This article is an open access article distributed under the terms and conditions of the Creative Commons Attribution (CC BY) license (http://creativecommons.org/licenses/by/4.0/). 